\title{
Selection and characterization of RNA aptamers to the RNA-dependent RNA polymerase from foot-and-mouth disease virus
}

\author{
MARK ELLINGHAM, DAVID H.J. BUNKA, DAVID J. ROWLANDS, and NICOLA J. STONEHOUSE \\ Institute of Molecular and Cellular Biology, Faculty of Biological Sciences and Astbury Centre for Structural Molecular Biology, University of Leeds, \\ Leeds, LS2 9JT, United Kingdom
}

\begin{abstract}
Foot-and-mouth disease virus causes a highly contagious disease of agricultural livestock and is of enormous economic importance. Replication of the RNA genome of the virus, via negative strand intermediates, involves an RNA-dependent RNA polymerase (3Dpol). RNA aptamers specific to this enzyme have been selected and characterized. Some of these molecules inhibit enzymatic activity in vitro, with $\mathrm{IC}_{50}$ values of $<20 \mathrm{nM}$ and $\mathrm{K}_{\mathrm{i}}$ values of 18-75 $\mathrm{nM}$. Two of these show similarity, both with each other and with regions of the viral genome. Furthermore, truncated versions of one of the aptamers have been used to define the parts of the molecule responsible for its inhibitory activity.
\end{abstract}

Keywords: aptamer; RNA polymerase; FMDV; in vitro selection; SELEX

\section{INTRODUCTION}

Foot-and-mouth disease (FMD) is one of the most important diseases of domestic livestock, affecting a wide range of species, especially cloven hoofed animals. Although not normally fatal, the disease is one of the most highly contagious known. It spreads rapidly and is estimated to result in a $25 \%$ loss in productivity if not controlled (Brooksby 1982). The causative agent, foot and mouth disease virus (FMDV) belongs to the family Picornaviridae, which includes many human and animal pathogens, including poliovirus (PV) and rhinovirus (the main causative agent of the common cold). FMDV is highly variable. There are seven distinct serotypes, and each of these comprises a wide range of strains. In common with all picornaviruses, the FMDV genome is a single-stranded, positive-sense RNA molecule of $\sim 8.5 \mathrm{~kb}$ comprising long $5^{\prime}$ and $3^{\prime}$ untranslated regions (UTRs) flanking a single open reading frame. The $5^{\prime}$ UTR is exceptionally long, $\sim 1.2 \mathrm{~kb}$ in length, and includes highly structured domains (Pilipenko et al. 1989; Mason et al. 2002, 2003). The

Reprint requests to: Nicola J. Stonehouse, Institute of Molecular and Cellular Biology, University of Leeds, Leeds, LS2 9JT, United Kingdom; e-mail: n.j.stonehouse@leeds.ac.uk; fax: 44-113-343-2835.

Article published online ahead of print. Article and publication date are at http://www.rnajournal.org/cgi/doi/10.1261/rna.161006. domain at the $5^{\prime}$ terminus is $\sim 400$ nucleotides (nt) in length and is predicted to form an imperfect hairpin structure (Newton et al. 1985). This is known as the S fragment and is separated from the remainder of the genome by a long (150-250 nt) poly-cytidylic acid tract. This, in turn, is followed by a region of pseudoknot repeats of unknown function (Clarke et al. 1987), a cis-acting replication element (cre) necessary for the uridylation of the peptide primer $(\mathrm{VPg})$ for RNA replication (Mason et al. 2002; Tiley et al. 2003), and finally an internal ribosome entry site (IRES) important for the initiation of translation (Belsham and Brangwyn 1990; Kuhn et al. 1990). By analogy with $\mathrm{PV}$, the $\mathrm{S}$ fragment is likely to be important in the initiation and control of RNA replication. The polyprotein product of the open reading frame is initially processed into four regions: the $\mathrm{L}$ proteinase, $\mathrm{P} 1$ to $2 \mathrm{~A}$, $2 \mathrm{BC}$, and $\mathrm{P} 3$. The latter three are further processed by virus-encoded proteases into the mature protein products. The structural proteins are derived from the N-terminal region (P1), and the proteins involved in viral replication occupy the C-terminal two thirds of the precursor polyprotein (P2, P3). The RNA-dependent RNA polymerase (RdRp), known as 3Dpol, responsible for replication of the genome (via negative strand intermediates), is located at the C-terminus of the polyprotein. Synthesis of the viral RNA is initiated by VPg, which undergoes post-translational uridylation by $3 \mathrm{Dpol}$ in conjunction with the precursor 
protein, 3CD, in the presence of cre (Nayak et al. 2005). cre is known to contain an essential AAACA motif; however, the details of the uridylation and priming mechanisms are poorly understood, and although these are common to all picornaviruses, there are a number of details that are unique to FMDV. In particular, the FMDV genome encodes three tandem copies of $\mathrm{VPg}$, in contrast to the single copy found in the genomes of all other picornaviruses (Forss and Schaller 1982). These sequence data supported earlier biochemical evidence for the presence of multiple VPgs on virion RNA (King et al. 1980). Together, these studies showed that the three encoded VPgs are used with equal frequency in RNA replication. It is tempting to speculate that this repetition of the VPg region of the genome is related to the rapid replication of FMDV compared to other picornaviruses.

The atomic structures of 3Dpol of FMDV in the apo form and in complex with a synthetic primer/template have been solved at resolutions of $1.9 \AA$ and $3 \AA$, respectively (Ferrer-Orta et al. 2004). This represents the first complete structure of a picornavirus polymerase and has the "palm, thumb, and fingertips" topology seen in other RdRps (O'Reilly and Kao 1998). Recently, the structure of 3Dpol complexed with the VPg primer peptide has also been published (Ferrer-Orta et al. 2006). Although these FMDV structures have significantly advanced our understanding of the properties of the polymerase, there are still many aspects of its function in replication or in the uridylation of VPg that are not fully understood. In an attempt to address some of these questions, we have selected specific molecular probes, RNA aptamers, as tools to dissect the functions of $3 \mathrm{Dpol}$.

Aptamers are small single-stranded nucleic acid molecules that exhibit some of the characteristics of both antibodies and siRNAs. They share a number of potential applications with monoclonal antibodies but may be selected to have even higher affinities and specificities. In addition, they can be modified to increase their stability and to facilitate delivery into cells (for reviews, see Blank and Blind 2005; Bunka and Stockley 2006). They are, therefore, useful as probes to define binding sites for the design of small-molecule inhibitory compounds or in diagnostics (Brody et al. 1999; Collett et al. 2005; YamamotoFujita and Kumar 2005; Bunka and Stockley 2006). As aptamers can be selected to directly inhibit an interaction, for example, between enzymes and their substrates or receptors and their ligands, it is clear that they could also have potential as therapeutics. A recent exciting development in this field has been the aptamer Macugen. This binds to vascular endothelial growth factor and is in clinical use for the treatment of age-related macular degeneration (Lee et al. 2005; Ng et al. 2006).

Aptamers are isolated using an in vitro selection technique, referred to as SELEX (systematic evolution of ligands by exponential enrichment) (Tuerk and Gold 1990;
Ellington and Szostak 1990) involving iterative rounds of target binding and preferential amplification. The technique can be applied to almost any target, and there are $\sim 3000$ aptamer sequences currently in the literature (http://aptamer.icmb.utexas.edu; Lee et al. 2004). However, targets from relatively few viruses are represented. Examples include aptamers to HIV Tat and reverse transcriptase (Ye et al. 1996; Nickens et al. 2003), hepatitis C virus (HCV) polymerase (see Biroccio et al. 2002; Vo et al. 2003) and NS3 (Nishikawa et al. 2003, 2004), influenza hemagglutinin (Jeon et al. 2004; Misono and Kumar 2005; Gopinath et al. 2006), and bacteriophage MS2 coat protein (Convery et al. 1998; Hirao et al. 1998; Rowsell et al. 1998; Shtatland et al. 2000). In this article, we report the identification and characterization of the first aptamers to any protein from FMDV; the 3Dpol enzyme (serotype C). Three of these RNA molecules display inhibitory activity in an in vitro UTP incorporation assay.

\section{RESULTS}

\section{Aptamers with similarity to the viral genome}

Lysine residues on the surface of 3Dpol were chemically biotinylated, allowing the enzyme to be immobilized onto the surface of steptavidin-coated magnetic beads. Fifteen rounds of selection were undertaken using a degenerate library of $\sim 10^{15}$ sequences, consisting of an $\mathrm{N}_{30}$ random region flanked by primer sequences for amplification and in vitro transcription. The SELEX procedure was carried out on a Biomek 2000 automated work station using protocols similar to those previously described by the Ellington Laboratory (Cox et al. 1998; Cox and Ellington 2001). As expected, the selected pool displayed increased affinity for 3Dpol compared with the naive RNA population as assessed by electrophoretic mobility shift assays (data not shown). Fifty-two cDNA clones were prepared from the round 15 selected pool, of which 25 were selected at random for detailed analysis and sequencing (Fig. 1A). Selection resulted in some of the aptamers incorporating $\mathrm{N}_{30}$ regions smaller than the original 30 nucleotides. The greatest reductions were seen with aptamers F4, F6, F12, and F38. Some minor mutations in the flanking sequences were also observed.

Sequence similarity was determined by using the GeneBee Multiple Alignment program (http://www.genebee. msu.su/services/malign_reduced.html). Two of the aptamers (referred to as F14 and F17) were identical and contained sequence motifs with significant similarity to sequences within the positive-sense viral genome, as did eight of the others (Fig. 1B). The remainder exhibited little similarity. The selected aptamers generally shared similarity with viral sequences clustered at the 5' UTR, especially in the first 364 nucleotides, corresponding to the $\mathrm{S}$ fragment. Similarity was also seen with the reverse complement of the genome 
A

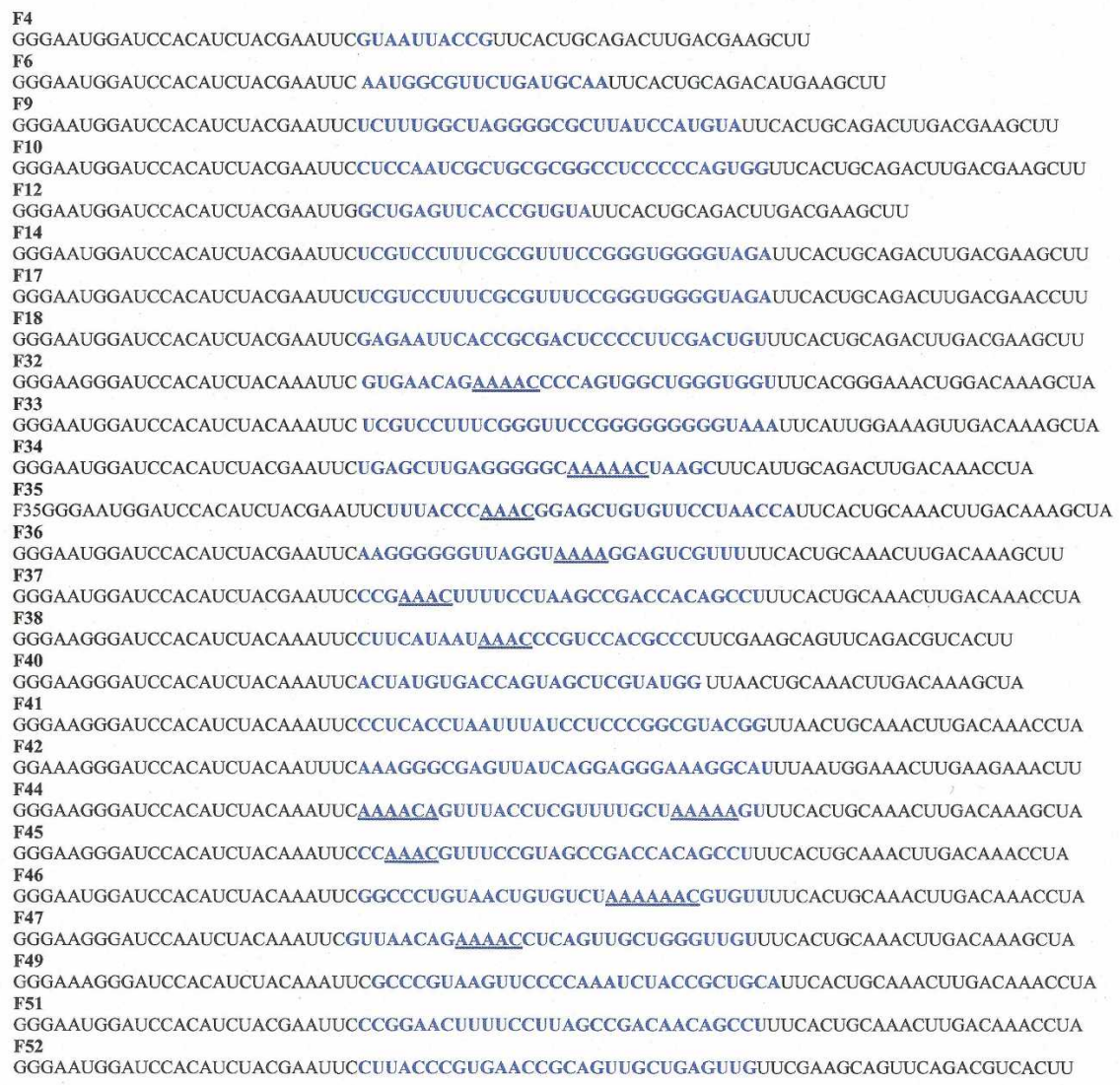

B

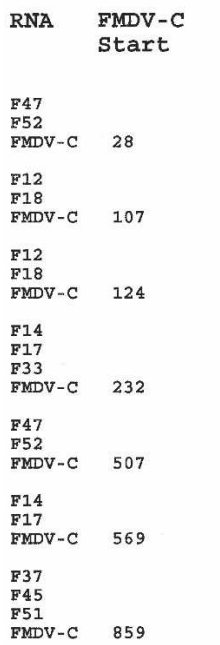

C RNA FMV-C RNA Sequence
Start 3' UTR F10 3' CUCCAAUÜGEUECECGGCCUCCCCCAGUGG FI8 11 3. GAGAAUU CACCECGACUCCCCUUCGACUGU

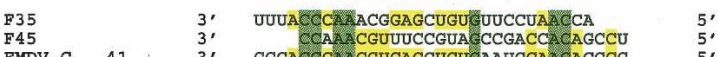
FMDV-C 41 3, GGGACECAACGUGAGGUGUGAAUGCARCACGCG

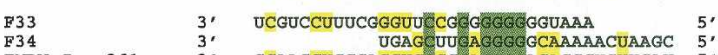

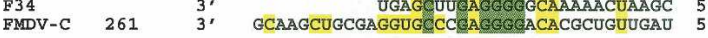
F36 3', AAGGGGGGUUAEG GUPAAAGGAGUCGUUU

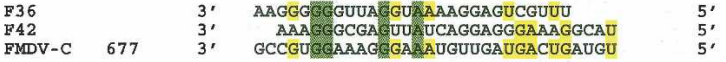

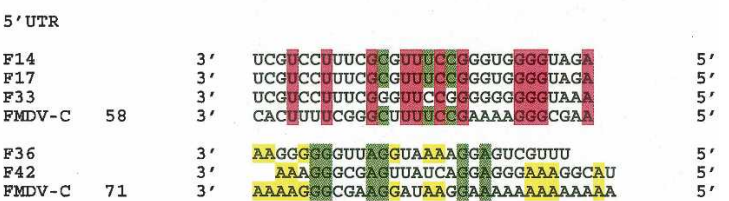

FIGURE 1. (A) Sequences of aptamers isolated from the RNA pool from the final round of selection against FMDV-C 3 Dpol. The $\mathrm{N}_{30}$ region is in blue, and runs of four or more As or AAAC motifs are underlined. $(B)$ A subset of the aptamers show sequence identity with each other and with the $5^{\prime}$ UTR of the genome of FMDV-C. The S fragment extends for the first $364 \mathrm{nt}$, and the start of cre is at nucleotide 605 . (C) There is also similarity with the $5^{\prime}$ and $3^{\prime}$ UTRs of the reverse complement. The aptamers are shown adjacent to the section of the genome with which they share similarity, and the numbering scheme used for $B$ and $C$ refers to nucleotide numbers in the positive and negative strands of the genome, respectively. Similarity between three aptamers and the genome is highlighted in pink, between two aptamers and the genome in green, and between one aptamer and the genome in yellow. 
to regions that correspond to the $3^{\prime}$ and $5^{\prime}$ UTRs of the negative strand during replication (Fig. 1C). Aptamers F14/ 17, F18, and F33 share similarity with both the genome and the reverse complement. Little similarity was found between any of the aptamers and the coding region or the $3^{\prime}$ end of the genome. It is possible that the similarity between some of the aptamers and regions of the $5^{\prime}$ end of the genome (and possibly the $3^{\prime}$ and $5^{\prime}$ ends of the negative strand) may represent preferred genomic binding sites of the enzyme during replication. Interestingly, runs of four or more As were seen in six aptamers (F32, F34, F36, F44, F46, and F47), and an AAAC motif was present in nine of the aptamers sequenced (F32, F34, F35, F37, F38, F44, F45, F46, and F47), the motif being AAACA for one of the aptamers (F44). This shares similarity with the conserved AAACA sequence of cre (Mason et al. 2002).

\section{Inhibition of polymerase function}

To investigate the ability of the anti-3Dpol aptamers to inhibit RNA synthesis, we employed polymerase activity assays that measured the incorporation of $\alpha-{ }^{32} \mathrm{P}$ UTP into an RNA product. The rate of incorporation is linear over a 2-h period (Fig. 2A). For the inhibition experiments, the polymerase was preincubated with selected aptamers at a range of concentrations for $15 \mathrm{~min}$, prior to assessing the ability of each aptamer to reduce polymerase activity after 1 h. As a negative control, identical assays were undertaken using the unselected $\mathrm{N}_{30}$ RNA pool. In previous studies using HCV polymerase, aptamers were selected that either displayed similarity with the viral genome (Biroccio et al. 2002) or showed no significant similarity (Vo et al. 2003). In similar polymerase inhibition assays, both classes were found to inhibit the function of the polymerase in vitro. It is likely that the two selections resulted in aptamers that recognize different sites (apatopes) on the target molecule and that may inhibit the enzyme by different mechanisms. In our study 22 aptamers were tested. These included all of the aptamers with similarity to the genome and negative strand listed in Figure 1, B and C (with the exception of F36), as well as eight others selected at random. Most of the aptamers had little effect on the enzyme, reducing the activity by $0 \%-23 \%$ at the highest concentration tested (100 nM). However, three were found to have more dramatic effects, resulting in $68 \%-93 \%$ reduction in activity. The data presented in Figure $2 \mathrm{~B}$ and Table 1 show that aptamers F38, F47, and F52 inhibit the enzyme at $\mathrm{IC}_{50}$ of $15.8 \pm 3.4 \mathrm{nM}, 10.6 \pm 2.1 \mathrm{nM}$, and $16.4 \pm 3.1 \mathrm{nM}$, respectively. As a negative control, identical assays were undertaken using the naive RNA pool, which showed no inhibitory activity. F47 and F52 share 76\% sequence identity in their $\mathrm{N}_{30}$ regions. They also share similarity with sections of the viral genome: $53 \%$ and $62 \%$ for F47 and F52, respectively, with the S fragment (nucleotides 2857 ) and $37 \%$ and $34 \%$, respectively, with a second region in the 5' UTR (nucleotides 507-536, 5' to the pseudoknot region; Fig. 1). The third inhibitory aptamer (F38) had little sequence similarity with the genome (positive or negative strand) or with the other aptamers. The specificity of the inhibitory aptamers (F38, F47, and F52) was investigated in a similar assay with the related polymerase from PV. It was found that the aptamers had no effect on the activity of this enzyme (Fig. 2C). The polymerases from FMDV-C and PV share $29 \%$ overall sequence identity, with $69 \%$ in the regions in contact with the primer/template and incoming NTP. The overall architecture of FMDV 3Dpol is similar to that seen in the crystal structure of PV polymerase (Thompson and Peersen 2004). In both structures, there are extensive interactions between thumb and finger domains, fully enclosing the active site. Furthermore, the shape and size of the central cavity (which accommodates primer/ template) are almost identical (Ferrer-Orta et al. 2006).
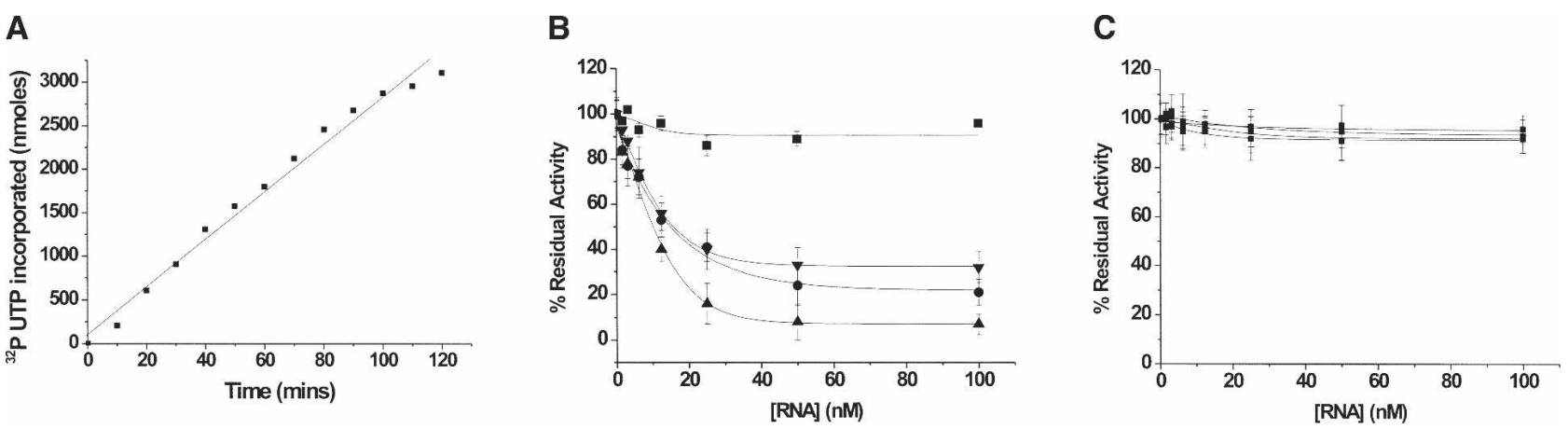

FIGURE 2. (A) Incorporation of $\alpha-{ }^{32} \mathrm{P}$ UTP by 3Dpol in the presence of a primer/template is linear over a 2-h period; $4 \mathrm{nM}$ FMDV 3Dpol was incubated with a $\alpha-{ }^{32} \mathrm{P}$ UTP substrate and primer/template. $(B)$ Aptamers F38 $(\bullet)$, F47 ( $\left.\mathbf{\Delta}\right)$, and F52 ( $)$, but not the naive RNA pool $(\boldsymbol{\square})$, inhibit FMDV 3Dpol; $4 \mathrm{nM}$ was incubated with a $\alpha-{ }^{32} \mathrm{P}$ UTP substrate, primer/template and increasing concentrations of aptamer RNA. The amount of $\alpha-{ }^{32} \mathrm{P}$ UTP incorporated into the polymer was measured, and the activity was calculated as a percentage of the activity of 3Dpol in the absence of aptamer. $(C)$ The same aptamers do not inhibit PV 3Dpol; $10 \mathrm{nM}$ PV 3Dpol was incubated with a $\alpha-{ }^{32} \mathrm{P}$ UTP substrate, primer/ template, and increasing concentrations of RNA as in $B$. 
TABLE 1. $\quad \mathrm{IC}_{50}$ and $\mathrm{K}_{\text {Dapp }}$ values for aptamer:3Dpol interaction derived from polymerase activity and affinity assays

\begin{tabular}{lcl}
\hline & $\mathrm{IC}_{50}(\mathrm{nM})$ & $\mathrm{K}_{\mathrm{D} \text { app }}(\mathrm{nM})$ \\
\hline F38 & $15.8 \pm 3.4$ & 460 \\
F47 & $10.6 \pm 2.1$ & $375 \pm 46$ \\
F52 & $16.4 \pm 3.1$ & 625 \\
F47tr & $10.2 \pm 1.6$ & 325 \\
\hline
\end{tabular}

\section{Affinity of aptamers for 3Dpol}

Binding affinities of the RNA aptamers for the $3 \mathrm{Dpol}$ protein were measured using a bead-based immobilization/ precipitation assay that we have developed (Robinson et al. 2006), similar to a method described previously (Bae et al. 2002; Hwang et al. 2004). Increasing amounts of biotinylated $3 \mathrm{Dpol}$ were immobilized onto streptavidin beads before incubation with $\alpha-{ }^{32} \mathrm{P}$ UTP radiolabeled RNA aptamers. The amount of aptamer bound was quantified by measuring RNA band intensity after electrophoresis and autoradiography of RNA eluted from the beads. By comparison with a maximum binding value, data are represented as a percentage of RNA bound, allowing calculation of the apparent dissociation constant ( $\left.\mathrm{K}_{\text {Dapp }}\right)$ (Fig. 3). $K_{\text {Dapp }}$ for the protein with the naive RNA pool control was estimated to be $4 \mu \mathrm{M}$, whereas for aptamers $\mathrm{F} 38, \mathrm{~F} 47$, and $\mathrm{F} 52, \mathrm{~K}_{\text {Dapp }}=$ $460 \mathrm{nM}, 375 \pm 46 \mathrm{nM}$, and $625 \mathrm{nM}$, respectively.

\section{Definition of aptamer minimal sequences}

The aptamer sequences described above are 75-80 nt in length, as in addition to the $\mathrm{N}_{30}$ random region, they included flanking primer sequences (Fig. 1). Any similarity to the viral genome was contained within the random region. Therefore, shortened templates were designed that encompassed the $\mathrm{N}_{30}$ regions and T7 RNA promoter site only. The truncated aptamers (F38tr, F47tr, and F52tr) were synthesized by in vitro transcription. As two Gs were added at the $5^{\prime}$ ends of the $\mathrm{N}_{30}$ region templates to facilitate transcription, this resulted in RNA molecules of 27-32 nt in length. A control RNA (referred to as viraltr) was also produced. This corre- sponded to nucleotides $28-57$ of the FMDV-C genome to which F47 and F52 share similarity (Fig. 4A). Truncation of aptamer F47 in this way did not significantly affect its binding affinity for $3 \mathrm{Dpol}\left(\mathrm{K}_{\text {Dapp }}=325 \mathrm{nM}\right.$ for $\mathrm{F} 47 \mathrm{tr}$, compared with $375 \pm 46 \mathrm{nM}$ for full-length aptamer F47) or its ability to inhibit polymerase activity $\left(\mathrm{IC}_{50}=10.2 \pm\right.$ 1.6 and $10.6 \pm 2.1 \mathrm{nM}$ for F47tr and F47, respectively) (Table 1; Fig. 4B). However, truncation of aptamers F38 and F52 resulted in the loss of inhibitory activity, despite the fact that F52tr shares $77 \%$ sequence similarity with F47tr. The viraltr RNA displayed no inhibitory activity in the assay.

Mfold secondary structure predictions (Zuker 2003) suggest that both aptamers F47 and F47tr contain an 18 nucleotide stem-loop that was not predicted in the noninhibitory viraltr sequence. To investigate the possible importance of this motif in recognition and inhibition of the 3Dpol enzyme, an oligonucleotide corresponding to this stem-loop was designed and synthesized by phosphoramidite chemistry and purified by high-pressure liquid

\section{c}

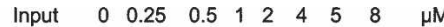

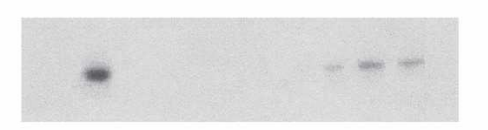

F38
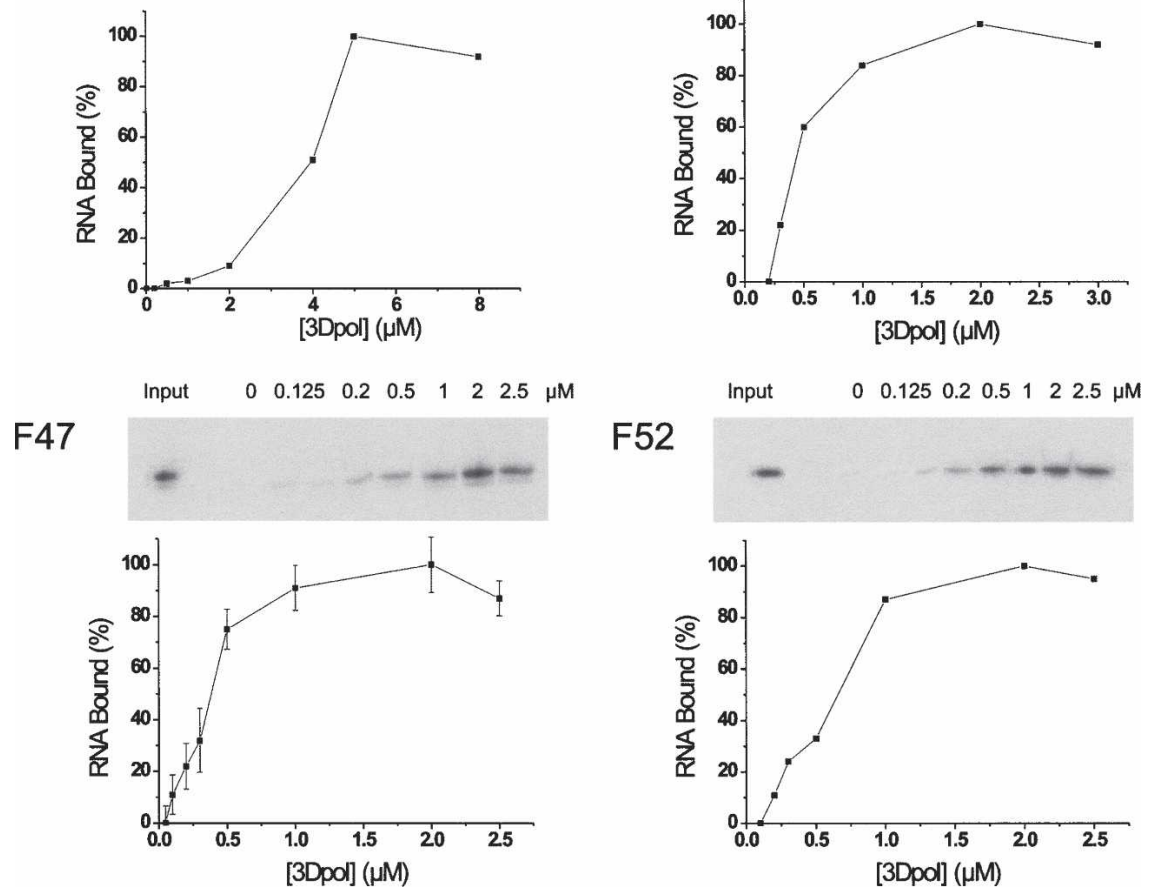

FIGURE 3. Binding affinities of aptamers F38, F47, and F52 and the naive RNA pool $(C)$ for the FMDV 3Dpol protein. Radiolabeled RNA aptamers $(10 \mathrm{nM})$ were incubated with increasing amounts of biotinylated 3Dpol protein. Bound RNA was eluted and electrophoresis undertaken on a $12 \%$ denaturing polyacrylamide gel, quantitated by autoradiography. Images of these gels are shown, with the concentration of 3Dpol used indicated for each lane. The percentage of input RNA bound to 3Dpol was calculated by determining the fraction of radioactivity present in each lane. The concentration of protein at which maximum binding of RNA to 3Dpol was observed was seen at $2 \mu \mathrm{M}$ with aptamers F38, F47, and F52, and $5 \mu \mathrm{M}$ for the control RNA (the naive RNA pool). The values measured have been normalized to these respective amounts. 


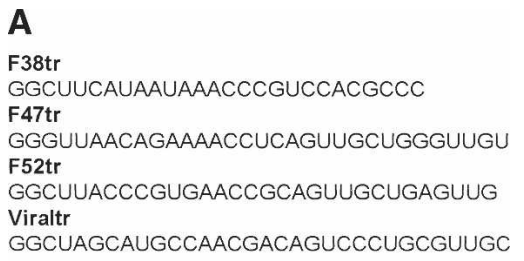

B

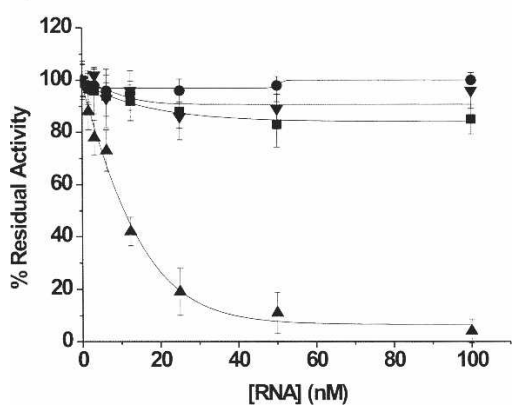

FIGURE 4. Definition of aptamer sequences. (A) Sequences of truncated aptamers that corresponded to the $\mathrm{N}_{30}$ region of each fulllength aptamer and two additional 5' G residues. (B) Truncated aptamers were assayed for their ability to inhibit the catalytic activity of 3Dpol in order to assess which parts of the sequences are important for this inhibition. Upon truncation, aptamers F38tr $(\bullet)$ and F52tr ( $)$ no longer inhibited 3Dpol, whereas the activity of aptamer F47tr (A) was unaffected, compared with a viraltr RNA control (nucleotides 28-57 of the FMDV-C genome) see $A(\mathbf{\square})$.

chromatography (HPLC) (Fig. 5A). The ability of this synthetic RNA to inhibit the activity of 3Dpol was measured, as described previously. The data from these $\alpha-{ }^{32} \mathrm{P}$ UTP incorporation assays (Fig. 5B) show that although the stem-loop does inhibit the 3Dpol, it was less effective than either the full-length or truncated 47 aptamer, reaching only a $30 \%$ reduction in polymerase activity (in the presence of $100 \mathrm{nM}$ aptamer). An extended RNA stem-loop incorporating two additional GC base pairs at the $5^{\prime}$ and $3^{\prime}$ ends, designed to increase the $T_{m}$, gave a similar result (32\% inhibition).

\section{Mode of aptamer inhibition}

The mode of inhibition by aptamers F38, F47, F52, and F47tr was investigated by carrying out $\alpha-{ }^{32} \mathrm{P}$ UTP incorporation assays using varying concentrations of primer/template similar to those described above, but in the presence of increasing amounts of aptamer RNA. This allowed comparison of calculated values of $\mathrm{V}_{\max }$ for the reaction, $\mathrm{K}_{\mathrm{m}}$ for the primer/template, and $\mathrm{K}_{\mathrm{i}}$. The data, illustrated in Figure 6 and Table 2, show that the presence of tRNA has little effect on either $V_{\max }$ or $K_{m}$. For all of the aptamers tested, however, $\mathrm{V}_{\max }$ values were reduced. $\mathrm{V}_{\max }$ in the absence of aptamer $=1664 \pm 92 \mathrm{nmol} / \mathrm{h}$. In the presence of $10 \mathrm{nM}$ or $100 \mathrm{nM}$ of F38, this decreased to $1131 \pm 75$ and $671 \pm 59 \mathrm{nmol} / \mathrm{h}$, respectively. A similar decrease was seen for F47 (1072 \pm 31 and $407 \pm 20 \mathrm{nmol} / \mathrm{h})$, F47tr $(976 \pm 67$ and $322 \pm 9 \mathrm{nmol} / \mathrm{h})$, and F52 (1467 \pm 103 and $814 \pm 103 \mathrm{nmol} / \mathrm{h}$ ) with $10 \mathrm{nM}$ or $100 \mathrm{nM}$ aptamer, respectively. The pattern for $\mathrm{K}_{\mathrm{m}}$ was more complicated. In the absence of aptamer, $\mathrm{K}_{\mathrm{m}}=346 \pm 40$ $\mathrm{nM}$. In the presence of aptamer F38 at 10 and $100 \mathrm{nM}$, $\mathrm{K}_{\mathrm{m}}=334 \pm 52$ and $295 \pm 60 \mathrm{nM}$, respectively. The lack of systematic variation in these values indicates that F38 inhibits the 3Dpol enzyme noncompetitively with respect to the primer/template RNA. More variation was seen with $\mathrm{K}_{\mathrm{m}}$ for the other aptamers tested $(508 \pm 37$ and $309 \pm 39$ $\mathrm{nM}$ for $\mathrm{F} 47,503 \pm 93$ and $215 \pm 13 \mathrm{nM}$ for F47tr, and $523 \pm 88$ and $443 \pm 79 \mathrm{nM}$ for F52 at $10 \mathrm{nM}$ and $100 \mathrm{nM}$, respectively). Under these conditions, aptamer F47tr had the lowest $\mathrm{K}_{\mathrm{i}}$ value $(14 \mathrm{nM})$, followed by F47 (18 nM) F38 $(21 \mathrm{nM})$, and $\mathrm{F} 52(75 \mathrm{nM}) . \mathrm{K}_{\mathrm{i}}$ values are related to $\mathrm{K}_{\mathrm{D}}$, and given that the lower the $\mathrm{K}_{\mathrm{i}}$, the more effective the inhibitor, this result confirms previous data indicating that F47 and F47tr are the best inhibitors.

\section{DISCUSSION}

We report the selection and characterization of RNA aptamers to the 3D RdRp, a key part of the FMDV replication complex. This is the first report of aptamer selection to any protein of this economically important

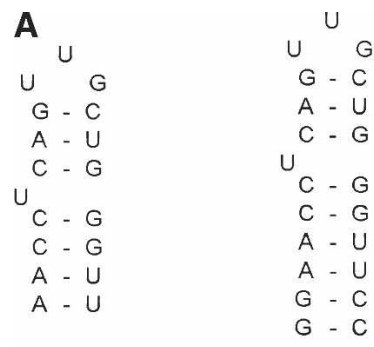

Stem-loop Extended stem-loop

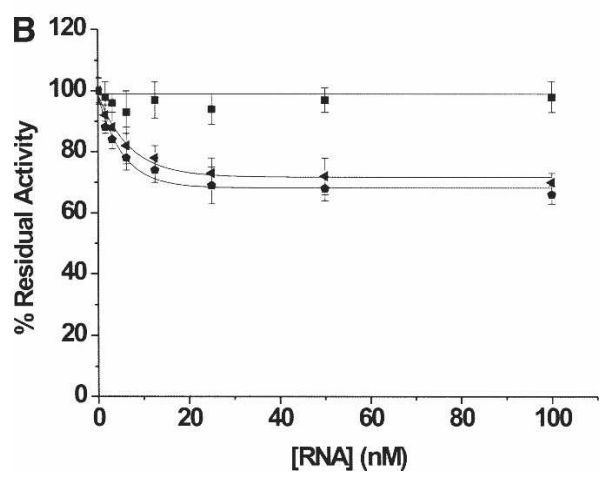

FIGURE 5. (A) The predicted secondary structure of the stem-loop of aptamer F47, together with an extended stem-loop incorporating two additional GC base-pairs. (B) The stem-loop (4) and the extended stem-loop $(\bullet)$ retain some ability to inhibit 3Dpol compared with data for the naïve RNA pool $(\mathbf{\square})$, showing an ability to reduce the catalytic activity of 3 Dpol by $\sim 30 \%$. 
A

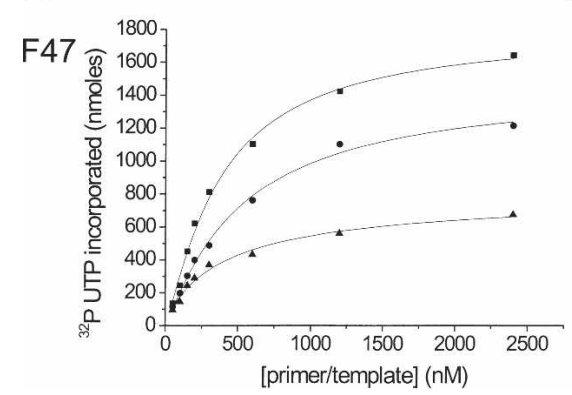

B

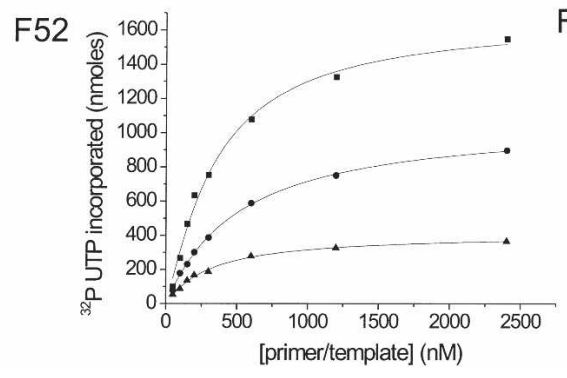

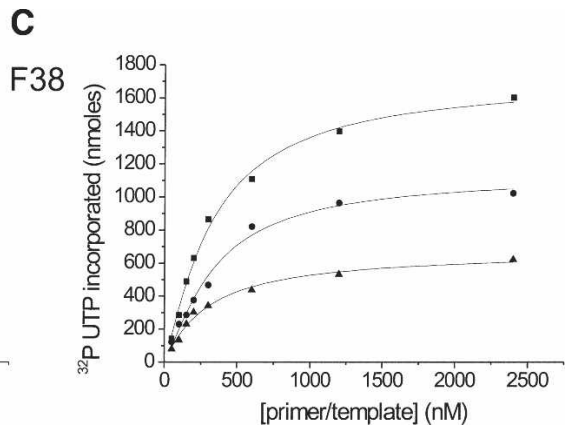

FIGURE 6. Inhibition of the 3Dpol interaction by aptamers F47 (A), F52 (B), and F38 (C). 3Dpol (8 nm) was incubated with various concentrations of each aptamer $(\square) 0 \mathrm{nM} ;\left(\begin{array}{l}\mathbf{O} \\ \mathbf{V}\end{array} 10 \mathrm{nM} ;(\boldsymbol{\Delta}) 100 \mathrm{nM}\right.$ and increasing amounts of primer/template for $1 \mathrm{~h}$. Kinetic parameters $\mathrm{V}_{\max }$ and $\mathrm{K}_{\mathrm{m}}$ were calculated using the Hill equation.

animal pathogen. We have characterized three aptamers (F38, F47, and F52) that inhibit the in vitro activity of the enzyme with $\mathrm{IC}_{50}$ values of $15.8 \mathrm{nM}, 10.6 \mathrm{nM}$, and 16.4 $\mathrm{nM}$, respectively. One aptamer retains this inhibitory ability when truncated to a $32 \mathrm{mer}$ (F47tr) with an $\mathrm{IC}_{50}$ of $10.2 \mathrm{nM}$.

Although they are efficient inhibitors, the aptamers show lower affinity for the enzyme than expected, with $\mathrm{K}_{\text {Dapp }}$ values of $325-625 \mathrm{nM}$. This is likely to be due to the technique used to measure $\mathrm{K}_{\text {Dapp }}$. Immobilization of 3Dpol to streptavidin beads involved biotinylation of surface lysines. Together with the steric effects of immobilization, this could result in a loss of apatopes and therefore produce a higher $K_{\text {Dapp }}$ than expected. Although the same strategy was employed to immobilize the protein as a selection target, it seems likely that the level of biotinylation was different in the two experiments. Unfortunately, there was an insufficient amount of biotinylated protein available to establish the extent of derivatization by mass spectrometry. The trend seen in the affinity assays, however, does mirror that of the inhibition studies, since aptamers F47 and F47tr have higher affinities ( $K_{\text {Dapp }}=325$ and $375 \mathrm{nM}$ ) for 3Dpol than F38 and F52 $\left(\mathrm{K}_{\text {Dapp }}=460\right.$ and $\left.625 \mathrm{nM}\right)$. A similar pattern is seen with the $K_{i}$ values. These are related to $K_{D}$ and are lower for aptamers F47 and F47tr (18 and $14 \mathrm{nM}$ ) than for aptamers F38 and F52 (21 and $75 \mathrm{nM}$, respectively). Furthermore, it therefore appears that the $K_{i}$ data more accurately reflect the affinity of the aptamer-apatope interaction. Further truncation of F47tr into an 18-nt stem-loop resulted in a substantial (but not total) loss of inhibition. This truncation involved the removal of the $5^{\prime}$ end of the molecule, and it is therefore likely that this region contributes to $3 \mathrm{Dpol}$ inhibition. In collaboration with Nuria Verdaguer (Barcelona), we have undertaken cocrystallization studies of F47tr with 3Dpol. From the difference maps, electron density was well defined, allowing the positioning of a fragment of single-stranded RNA (six of the 32 bases) in the central cavity. Additional density was also visible, accommodating two or three aptamer bases loosely contacting the fingertip region. Both regions of density were compatible with the binding of singlestranded RNA. Although these observations are very preliminary, refinement of the complex is now in progress $(\mathrm{N}$. Verdaguer, pers. comm.).

Similarity with the viral genome is not necessarily indicative of inhibitory activity. Aptamers F47tr and F52tr share $50 \%$ and $58 \%$ similarity with the S fragment, $34 \%$ and $32 \%$ to a second region within the $5^{\prime}$ UTR, and $77 \%$ sequence identity with each other; however, only $47 \mathrm{tr}$ is inhibitory. Of the other aptamers characterized from the initial pool, several had similarities of up to $47 \%$ (in the $\mathrm{N}_{30}$ regions) with the viral genome (F14/F17 and F33), but none of these showed significant inhibition. The $\mathrm{N}_{30}$ region of F14/F17 also showed 47\% similarity with the negative strand of the genome. Furthermore, the inhibitory aptamer F38 shows little genome similarity. This is suggestive that the inhibitory aptamers may recognize a range of 3Dpol apatopes. From the kinetic data, aptamer F38 appears to exhibit a noncompetitive mode of inhibition. The data for aptamers F52, F47, and F47tr are less clear. From the preliminary structural studies described above, it appears that F47tr binds both in the active site of the polymerase in

\begin{tabular}{|c|c|c|c|}
\hline & $\begin{array}{c}\mathrm{V}_{\max } \\
\text { nmoles/hr }\end{array}$ & $\mathrm{K}_{\mathrm{m}} \mathrm{nM}$ & $\mathrm{K}_{\mathrm{i}} \mathrm{nM}$ \\
\hline $0 \mathrm{nM}$ aptamer & $1664 \pm 92$ & $346 \pm 40$ & ND \\
\hline 10 nM F38 & $1131 \pm 80$ & $334 \pm 52$ & 21 \\
\hline 100 nM F38 & $671 \pm 59$ & $295 \pm 60$ & \\
\hline 10 nM F47 & $1072 \pm 31$ & $508 \pm 37$ & 18 \\
\hline 100 nM F47 & $407 \pm 20$ & $309 \pm 39$ & \\
\hline 10 nM F52 & $1467 \pm 103$ & $523 \pm 88$ & 75 \\
\hline 100 nM F52 & $814 \pm 103$ & $443 \pm 79$ & \\
\hline $10 \mathrm{nM} \mathrm{F} 47 \mathrm{tr}$ & $976 \pm 67$ & $503 \pm 93$ & 14 \\
\hline $100 \mathrm{nM} \mathrm{F} 47 \mathrm{tr}$ & $322 \pm 9$ & $215 \pm 13$ & \\
\hline $10 \mathrm{nM}$ tRNA & $1447 \pm 32$ & $365 \pm 21$ & ND \\
\hline $100 \mathrm{nM}$ tRNA & $1408 \pm 23$ & $381 \pm 41$ & \\
\hline
\end{tabular}

ND indicates not determined. 
the central cavity and to a region distant from this, and therefore, the aptamer may inhibit both competitively and noncompetitively. From the electron density, however, it is impossible to distinguish between a model in which two RNA aptamers have bound to a single molecule of 3Dpol at the two sites or one in which a single RNA binds at both sites on the protein, but the intervening RNA sequence is too unstructured to give a signal. The similarity between aptamers F47 and F52 with regions in the $5^{\prime}$ UTR could suggest preferred genomic binding sites for 3Dpol during replication. Furthermore, aptamers F47 and F47tr contain an AAAC motif, which is also present in eight others (F32, F34, F35, F37, F38, F44, F45, and F46). This shares similarity with the conserved AAACA sequence of cre (Mason et al. 2002) and may reflect cre-3Dpol interactions during uridylation of VPg as well as a preference by 3Dpol for binding AAAC sequences, which are distributed throughout the $5^{\prime}$ UTR and the genome.

Aptamers F38, F47, and F52 are specific to FMDV and do not inhibit the related polymerase from PV. This is likely to reflect subtle differences in the structures of the two polymerases, and could be informative with respect to modeling the site of aptamer interaction. However, in order to fully understand replication in this virus and to probe the fine details of the interactions, it will be necessary to raise and characterize aptamers to other components of the FMDV replicase machinery for use in structural studies as well as in vitro and in vivo assays.

\section{MATERIALS AND METHODS}

\section{In vitro selection}

Selections against FMDV-C 3Dpol using a degenerate library of $\sim 10^{15}$ RNA sequences were undertaken using the following protocol.

The library (5'-GATAATACGACTCACTATAGGGAATGGAT CCACACATCTACGA-N ${ }_{30-}$ TTCGAAGCAGTTCAGACGTCACTT-3') consisted of a 30-mer random region, flanked with conserved primer sequences for PCR amplification and a T7 polymerase promoter sequence (highlighted in bold) for in vitro transcription. The initial pool was generated by subjecting the DNA library to 15 cycles of PCR in a $50 \mu \mathrm{L}$ volume containing a final concentration of $5 \mathrm{mM}$ Tris- $\mathrm{HCl}$ ( $\mathrm{pH} 8.0$ ), $10 \mathrm{mM} \mathrm{NaCl}, 10 \mu \mathrm{M}$ EDTA, $0.1 \mathrm{mM}$ DTT, $5 \%$ glycerol, $0.1 \%$ Triton X-100, $1.5 \mathrm{mM} \mathrm{MgCl}_{2}, 10 \mathrm{nM}$ template, $500 \mu \mathrm{M}$ of each dNTP, 1 unit (according to the manufacturer's instructions) of Taq DNA polymerase (Promega), and $1 \mu \mathrm{M}$ each of the upstream and downstream primers specific to the template: 5'-GATAATACGACTCACTATAGGGAATGGATC CACACATCTACGA-3', 5' -AAGCTTCGTCAAGTCTGCAGTGAA-3'.

C-His-tagged 3Dpol (2.4 nmol) (a gift from Esteban Domingo, Madrid) was biotinylated with EZ-Link Sulpho-NHS-LC-LCBiotin reagent (Pierce). This allowed immobilization onto streptavidin-coated magnetic MyOne beads (Dynal Biotech) at $10 \mathrm{mg} / \mathrm{mL}$ in selection buffer (50 mM Tris- $\mathrm{HCl}$ at $\mathrm{pH}$ 7.5, $100 \mathrm{mM}$ $\mathrm{NaCl}, 1 \mathrm{mM}$ dithiothreitol [DTT], $1 \mathrm{mM}$ EDTA). As lysine residues may be involved in RNA binding, care was taken to ensure only partial biotinylation occurred. In order to ensure a low level of biotinylation, the protein was incubated with the EZ-Link reagent for $30 \mathrm{~min}$, rather than the $2 \mathrm{~h}$ recommended by the manufacturer. Binding to magnetic beads was confirmed spectrophotometrically by calculating the concentration of supernatant protein $(\lambda=280$ $\mathrm{nm}$ ) before and after incubation with the support beads. After PCR, the $\mathrm{N}_{30}$ library was subjected to in vitro transcription, by incubating with $40 \mathrm{mM}$ Tris- $\mathrm{HCl}$ (pH 7.9), $8 \mathrm{mM} \mathrm{MgCl}_{2}, 25 \mathrm{mM} \mathrm{NaCl}, 2 \mathrm{mM}$ spermidine, and $500 \mu \mathrm{M}$ each of ATP, CTP, GTP, and UTP and 1.75 units of T7 RNA polymerase. Reactions were overlaid with mineral oil and incubated at $37^{\circ} \mathrm{C}$ for $1 \mathrm{~h}$. The product of this transcription was incubated for $5 \mathrm{~min}$ at room temperature with 100 pmol of 3Dpol in selection buffer before magnetic separation of the immobilized protein and removal of supernatant unbound RNA. After washing twice with selection buffer, any RNA that was bound to 3Dpol was eluted by incubating the immobilized protein in pure water (Sigma) for $15 \mathrm{~min}$ at $96^{\circ} \mathrm{C}$. This eluate was subjected to reverse transcription by first incubating with $1.25 \mu \mathrm{M}$ downstream primer, and $500 \mu \mathrm{M}$ of each dNTP for $15 \mathrm{~min}$ at $65^{\circ} \mathrm{C}$, followed by incubation with 1.75 units Superscript II (Invitrogen) for $1 \mathrm{~h}$ at $37^{\circ} \mathrm{C}$ with a final concentration of $50 \mathrm{mM}$ Tris- $\mathrm{HCl}$ ( $\mathrm{pH} 8.3$ ), $75 \mathrm{mM} \mathrm{KCl}$, and $3 \mathrm{mM} \mathrm{MgCl}_{2}$. Five microliters of the reverse-transcription product were subjected to PCR before being used as the sequence pool for the next round of selection, of which 14 subsequent rounds were performed using a Biomek 2000 Automated Workstation (Beckman Coulter). Negative selection against biotinylated beads alone was carried out prior to rounds 1, 6, and 11 to reduce the likelihood of aptamer selection against the streptavidin beads.

\section{RNA synthesis}

In vitro transcription reactions were carried out in a $20 \mu \mathrm{L}$ reaction volume containing $40 \mathrm{mM}$ Tris- $\mathrm{HCl}(\mathrm{pH}$ 7.9), $6 \mathrm{mM}$ $\mathrm{MgCl}_{2}, 10 \mathrm{mM} \mathrm{NaCl}$, and $2 \mathrm{mM}$ spermidine. The mixture also contained $500 \mu \mathrm{M}$ each of ATP, CTP, GTP, and UTP; 1.75 units of T7 RNA polymerase, according to the manufacturer's instructions (Promega); and $5 \mu \mathrm{L}$ DNA template from a PCR reaction. After incubation for $1 \mathrm{~h}$ at $37^{\circ} \mathrm{C}$, RNA was subjected to acidified phenol:chloroform extraction and ethanol precipitation. The RNA was analyzed using a 12\% (w/v) 19:1 acrylamide:bis-acrylamide denaturing polyacrylamide gel in TBE buffer ( $89 \mathrm{mM}$ Tris base, 89 $\mathrm{mM}$ boric acid, $2.5 \mathrm{mM}$ EDTA) and $7 \mathrm{M}$ urea and confirmed to be a single band.

The 18- and 22-mer stem-loops derived from the aptamer F47 sequence were synthesized using solid-phase 2'-ACE phosphoramidite chemistry (Dharmacon Inc.) (Scaringe et al. 1998). Purification was achieved by HPLC on a DNAPac PA100 column (Dionex) eluting with a $0-1 \mathrm{M} \mathrm{NaCl}$ gradient at $65^{\circ} \mathrm{C}$. Samples were desalted using a HiPrep 26/10 Desalting Column (Amersham Biosciences), eluting with $\mathrm{H}_{2} \mathrm{O}$ (Murray et al. 1994).

\section{Polymerase activity assays}

Incorporation of $\alpha-{ }^{32} \mathrm{P}$-labeled UTP into nascent transcripts by FMDV 3Dpol was investigated as an assay of polymerase activity. Assays were undertaken using $2 \mu \mathrm{g}$ Poly-(A) template (average length, 320) (Amersham), $2.4 \mu \mathrm{M}$ primer (oligo d(U) $)_{15}$ ), and 200 $\mu \mathrm{M}$ UTP; $5 \mu \mathrm{Ci} \alpha-{ }^{32} \mathrm{P}-\mathrm{UTP}$; and a final concentration of $30 \mathrm{mM}$ MOPS (pH 7.0), $25 \mathrm{mM} \mathrm{NaCl}, 5 \mathrm{mM} \mathrm{Mg}\left(\mathrm{CH}_{3} \mathrm{COO}\right)_{2}$, in a volume of $46 \mu \mathrm{L}$. The reaction was started by adding FMDV-C 3Dpol to 
a final concentration of $4 \mathrm{nM}$. Samples were incubated at $30^{\circ} \mathrm{C}$ for up to $2 \mathrm{~h}$ for the time-course experiment and for $1 \mathrm{~h}$ for inhibition studies. Reactions were stopped by adding $10 \mu \mathrm{L}$ of $0.5 \mathrm{M}$ EDTA. Ten microliters of each reaction were spotted onto separate DE-81 filters and washed with $200 \mathrm{~mL} 0.2 \mathrm{M} \mathrm{Na}_{2} \mathrm{HPO}_{4}$ five times, before

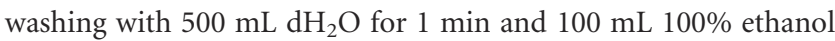
for a further minute. The filter squares were then air dried at room temperature for $1 \mathrm{~h}$ and the radioactivity quantified by scintillation counting. As a negative control, identical assays were undertaken using the naive RNA pool. Assays were performed in triplicate to allow the calculation of standard errors. Similar assays were also undertaken with PV 3Dpol (a gift from Jim Hogle, Harvard, Cambridge, MA) at $10 \mathrm{nM}$ concentration.

\section{Affinity measurements}

Bead-based affinity assays were employed with individual aptamers to measure their affinity for the 3 Dpol protein. These were similar to those employed previously to investigate aptamer affinity (Bae et al. 2002; Hwang et al. 2004). 3Dpol protein was biotinylated and immobilized onto streptavidin-coated magnetic beads (as above). Varying amounts of immobilized protein were incubated with $10 \mathrm{nM} \alpha{ }^{32} \mathrm{P}$-UTP-labeled RNA, in $30 \mathrm{mM}$ MOPS ( $\mathrm{pH} 7.0$ ), $25 \mathrm{mM} \mathrm{NaCl}$, and $5 \mathrm{mM} \mathrm{Mg}\left(\mathrm{CH}_{3} \mathrm{COO}\right)_{2}$. After $15 \mathrm{~min}$, the immobilized protein was pelleted and the supernatant, containing unbound RNA, was removed. RNA bound to the protein was eluted by adding water and heating to $96^{\circ} \mathrm{C}$ for $5 \mathrm{~min}$ before electrophoresis on a 12\% (w/v) 19:1 acrylamide:bis-acrylamide polyacrylamide gel containing TBE buffer ( $89 \mathrm{mM}$ Tris base, 89 $\mathrm{mM}$ boric acid, $2.5 \mathrm{mM}$ EDTA) and $7 \mathrm{M}$ urea. The concentration of protein at which maximum RNA binding was observed was used as a standard for calculating the $\mathrm{K}_{\text {Dapp }}$. After autoradiography, band intensity was quantified by using GeneSnap imaging software (Syngene). The percentage of RNA bound was calculated by using the concentration of protein that showed maximum RNA binding as a reference. This was plotted against concentration of 3Dpol, allowing calculation of the $\mathrm{K}_{\text {Dapp }}$ (Bae et al. 2002; Robinson et al. 2006). As a negative control, identical assays were undertaken using the naive RNA pool.

\section{Kinetic assays}

The mechanism of inhibition of each aptamer was determined with respect to the template/primer RNA. Inhibition assays were carried out under conditions as described above but with $8 \mathrm{nM}$ $3 \mathrm{Dpol}$ and increasing concentrations of poly $(\mathrm{A}) / \mathrm{oligo}(\mathrm{U})$ template/primer and RNA aptamer. After $1 \mathrm{~h}$, the amount of $\alpha-{ }^{32} \mathrm{P}$ UTP incorporated into the polymer was calculated, enabling the $\mathrm{V}_{\max }$ of the reaction and $\mathrm{K}_{\mathrm{m}}$ for the primer/template to be determined at various concentrations of each aptamer using the Hill equation (Equation 1). $\mathrm{K}_{\mathrm{i}}$ values were calculated using Equation 2.

$$
\begin{gathered}
y=V_{\max } \frac{x^{n}}{k^{n}+x^{n}} \\
V_{\max }=\frac{V_{\max }}{\left(1+[I] / K_{i}\right)}
\end{gathered}
$$

\section{ACKNOWLEDGMENTS}

We thank Esteban Domingo and Armando Arias (Madrid) for the gift of 3Dpol protein and Jim Hogle (Harvard) for the gift of poliovirus polymerase. We thank all of our collaborators, including Nuria Verdaguer (Barcelona) for useful discussions and are grateful to Alan Berry for help with interpretation of the kinetic data. M.E. was supported by a BBSRC studentship.

Received June 5, 2006; accepted August 22, 2006.

\section{REFERENCES}

Bae, S.-J., Oum, J.-H., Sharma, S., Park, J., and Lee, S.-W. 2002. In vitro selection of specific RNA inhibitors of NFATc. Biochem. Biophys. Res. Commun. 298: 486-492.

Belsham, G.J. and Brangwyn, J.K. 1990. A region of the 5' noncoding region of foot-and-mouth disease virus RNA directs efficient internal initiation of protein synthesis within cells: Involvement with the role of L protease in translational control. J. Virol. 64: 5389-5395.

Biroccio, A., Hamm, J., Incitti, I., De Francesco, R., and Tomei, L. 2002. Selection of RNA aptamers that are specific and high-affinity ligands of the hepatitis C virus RNA-dependent RNA polymerase. J. Virol. 76: 3688-3696.

Blank, M. and Blind, M. 2005. Aptamers as tools for target validation. Curr. Opin. Chem. Biol. 9: 336.

Brody, E.N., Willis, M.C., Smith, J.D., Jayasena, S., Zichi, D., and Gold, L. 1999. The use of aptamers in large arrays for molecular diagnostics. Mol. Diagn. 4: 381-388.

Brooksby, J.T. 1982. Portraits of viruses: Foot-and-mouth disease virus. Intervirology 18: 1-23.

Bunka, D.H.J. and Stockley, P.G. 2006. Aptamers come of age-at last!. Nat. Rev. Microbiol. 44: 589-596.

Clarke, B.E., Brown, A.L., Currey, K.M., Newton, S.E., Rowlands, D.J., and Carroll, A.R. 1987. Potential secondary and tertiary structure in the genomic RNA of foot and mouth disease virus. Nucleic Acids Res. 15: 7067-7079.

Collett, J.R., Cho, E.J., and Ellington, A.D. 2005. Production and processing of aptamer microarrays. Methods 37: 4-15.

Convery, M.A., Stonehouse, N.J., Rowsell, S., Ellington, A.D., Hirao, I., Adams, C.J., Peabody, D.S., Phillips, S.E.V., and Stockley, P.G. 1998. Crystal structure of an RNA-aptamer complex at 2.8A resolution. Nat. Struct. Biol. 5: 133-139.

Cox, J.C. and Ellington, A.D. 2001. Automated selection of antiprotein aptamers. Bioorg. Med. Chem. 9: 2525-2531.

Cox, J.C., Rudolph, P., and Ellington, A.D. 1998. Automated RNA selection. Biotechnol. Prog. 14: 845-850.

Ellington, A.D. and Szostak, J.W. 1990. In vitro selection of RNA molecules that bind specific ligands. Nature 346: 818-822.

Ferrer-Orta, C., Arias, A., Perez-Luque, R., Escarmis, C., Domingo, E., and Verdaguer, N. 2004. Structure of foot-and-mouth disease virus RNA-dependent RNA polymerase and its complex with a template-primer RNA. J. Biol. Chem. 279: 47212-47221.

Ferrer-Orta, C., Arias, A., Agudo, R., Pérez-Luque, R., Escarmís, C., Domingo, E., and Verdaguer, N. 2006. The structure of a protein primer-polymerase complex in the initiation of genome replication. EMBO J. 25: 880-888.

Forss, S. and Schaller, H. 1982. A tandem repeat gene in a picornavirus. Nucleic Acids Res. 12: 6587-6601.

Gopinath, S.C., Misono, T.S., Kawasaki, K., Mizuno, T., Imai, M., Odagiri, T., and Kumar, P.K. 2006. An RNA aptamer that distinguishes between closely related human influenza viruses and inhibits haemagglutinin-mediated membrane fusion. J. Gen. Virol. 87: 479-487.

Hirao, I., Spingola, M., Peabody, D., and Ellington, A.D. 1998. The limits of specificity: An experimental analysis with RNA aptamers to MS2 coat protein variants. Mol. Divers 4: 75-89. 
Hwang, B., Cho, J.S., Yeo, H.J., Kim, J.-H., Chung, K.M., Han, K., Jang, S.K., and Lee, S.-W. 2004. Isolation of specific and highaffinity RNA aptamers against NS3 helicase domain of hepatitis C virus. RNA 10: 1277-1290.

King, A.M., Sangar, D.V., Harris, T.J., and Brown, F. 1980. Heterogeneity of the genome-linked protein of foot-and-mouth disease virus. J. Virol. 34: 627-634.

Kuhn, R., Luz, N., and Beck, E. 1990. Functional analysis of the internal translation initiation site of foot-and-mouth disease virus. J. Virol. 64: 4625-4631.

Lee, J.F., Hesselberth, J.R., Meyers, L.A., and Ellington, A.D. 2004. Aptamer database. Nucleic Acids Res. 32: D95-100.

Lee, J.H., Canny, M.D., De Erkenez, A., Krilleke, D., Ng, Y.S., Shima, D.T., Pardi, A., and Jucker, F. 2005. A therapeutic aptamer inhibits angiogenesis by specifically targeting the heparin binding domain of VEGF165. Proc. Natl. Acad. Sci. 102: 18902-18907.

Mason, P.W., Bezborodova, S.V., and Henry, T.M. 2002. Identification and characterization of a cis-acting replication element (cre) adjacent to the internal ribosome entry site of foot-and-mouth disease virus. J. Virol. 76: 9686-9694.

Mason, P.W., Grubman, M.J., and Baxt, B. 2003. Molecular basis of pathogenesis of FMDV. Virus Res. 91: 9-32.

Misono, T.S. and Kumar, P.K.R. 2005. Selection of RNA aptamers against human influenza virus hemagglutinin using surface plasmon resonance. Anal. Biochem. 342: 312.

Murray, J.B., Collier, A.K., and Arnold, J.R.P. 1994. A general purification procedure for chemically synthesized oligoribonucleotides. Anal. Biochem. 218: 177.

Nayak, A., Goodfellow, I.G., and Belsham, G.J. 2005. Factors required for the Uridylylation of the foot-and-mouth disease virus 3B1, 3B2, and 3B3 peptides by the RNA-dependent RNA polymerase (3Dpol) in vitro. J. Virol. 79: 7698-7706.

Newton, S.E., Carroll, A.R., Campbell, R.O., Clarke, B.E., and Rowlands, D.J. 1985. The sequence of foot-and-mouth disease virus RNA to the 5' side of the poly $(\mathrm{C})$ tract. Gene 40: 331-336.

Ng, E.W., Shima, D.T., Calias, P., Cunningham Jr., E.T., Guyer, D.R., and Adamis, A.P. 2006. Pegaptanib, a targeted anti-VEGF aptamer for ocular vascular disease. Nat. Rev. Drug Discov. 5: 123-132.

Nickens, D.G., Patterson, J.T., and Burke, D.H. 2003. Inhibition of HIV-1 reverse transcriptase by RNA aptamers in Escherichia coli. RNA 9: 1029-1033.

Nishikawa, F., Kakiuchi, N., Funaji, K., Fukuda, K., Sekiya, S., and Nishikawa, S. 2003. Inhibition of HCV NS3 protease by RNA aptamers in cells. Nucleic Acids Res. 31: 1935-1943.

Nishikawa, F., Funaji, K., Fukuda, K., and Nishikawa, S. 2004. In vitro selection of RNA aptamers against the HCV NS3 helicase domain. Oligonucleotides 14: 114-129.
O’Reilly, E.K. and Kao, C.C. 1998. Analysis of RNA-dependent RNA polymerase structure and function as guided by known polymerase structures and computer predictions of secondary structure. Virology 252: 287-303.

Pilipenko, E.V., Blinov, V.M., Chernov, B.K., Dmitrieva, T.M., and Agol, V.I. 1989. Conservation of the secondary structure elements of the $5^{\prime}$-untranslated region of cardio- and aphthovirus RNAs. Nucleic Acids Res. 17: 5701-5711.

Robinson, M.A., Wood, J.P.A., Capaldi, S.A., Baron, A.J., Gell, C., Smith, D.A., and Stonehouse, N.J. 2006. Affinity of molecular interactions in the bacteriophage f29 packaging motor. Nucleic Acids Res. 34: 2698-2709.

Rowsell, S., Stonehouse, N.J., Convery, M.A., Adams, C.J., Ellington, A.D., Hirao, I., Peabody, D.S., Stockley, P.G., and Phillips, S.E.V. 1998. Crystal structures of a series of RNA aptamers complexed to the same protein target. Nat. Struct. Mol. Biol. 5: 970.

Scaringe, S.A., Wincott, F.E., and Caruthers, M.H. 1998. Novel RNA synthesis method using $5^{\prime}$-O-silyl-2'-O-orthoester protecting groups. J. Am. Chem. Soc. 120: 11820-11821.

Shtatland, T., Gill, S.C., Javornik, B.E., Johansson, H.E., Singer, B.S., Uhlenbeck, O.C., Zichi, D.A., and Gold, L. 2000. Interactions of Escherichia coli RNA with bacteriophage MS2 coat protein: Genomic SELEX. Nucleic Acids Res. 28: E93.

Tiley, L., King, A.M., and Belsham, G.J. 2003. The foot-and-mouth disease virus cis-acting replication element (cre) can be complemented in trans within infected cells. J. Virol. 77: 22432246.

Thompson, A.A. and Peersen, O.B. 2004. Structural basis for proteolysis-dependent activation of the poliovirus RNA-dependent RNA polymerase. EMBO J. 23: 3462-3471.

Tuerk, C. and Gold, L. 1990. Systematic evolution of ligands by exponential enrichment: RNA ligands to bacteriophage T4 DNA polymerase. Science 249: 501-510.

Vo, N.V., Oh, J.-W., and Lai, M.M.C. 2003. Identification of RNA ligands that bind hepatitis $\mathrm{C}$ virus polymerase selectively and inhibit its RNA synthesis from the natural viral RNA templates. Virology 307: 301.

Yamamoto-Fujita, R. and Kumar, P.K. 2005. Aptamer-derived nucleic acid oligos: applications to develop nucleic acid chips to analyze proteins and small ligands. Anal. Chem. 77: 5460-5466.

Ye, X., Gorin, A., Ellington, A.D., and Patel, D.J. 1996. Deep penetration of an alpha-helix into a widened RNA major groove in the HIV-1 rev peptide-RNA aptamer complex. Nat. Struct. Biol. 3: $1026-1033$.

Zuker, M. 2003. Mfold web server for nucleic acid folding and hybridization prediction. Nucleic Acids Res. 31: 3406-3415. 

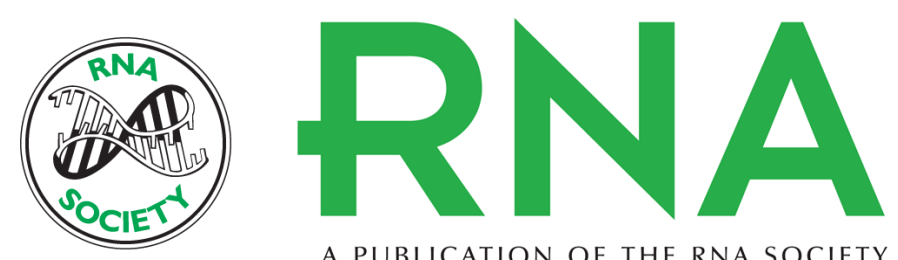

A PUBLICATION OF THE RNA SOCIETY

\section{Selection and characterization of RNA aptamers to the RNA-dependent RNA polymerase from foot-and-mouth disease virus}

Mark Ellingham, David H.J. Bunka, David J. Rowlands, et al.

RNA 2006 12: 1970-1979 originally published online October 3, 2006

Access the most recent version at doi:10.1261/rna.161006

References This article cites 46 articles, 12 of which can be accessed free at: http://rnajournal.cshlp.org/content/12/11/1970.full.html\#ref-list-1

License

Email Alerting Receive free email alerts when new articles cite this article - sign up in the box at the Service top right corner of the article or click here. 